\title{
Competitividade na regulamentação do transporte rodoviário de passageiros: uma análise à luz de um modelo de auditagem
}

\author{
Fernando Antonio Oliveira Rolim¹; Anísio Brasileiro²
}

\begin{abstract}
Resumo: Este artigo apresenta os resultados da aplicação de um modelo de auditagem sobre as regulamentações e instituições dos sistemas de Transporte Intermunicipal Convencional de Passageiros por Ônibus (TIPO) de três estados brasileiros, bem como sobre o sistema nacional de Transporte Interestadual por Ônibus (TRIP). O modelo apresenta boas práticas regulatórias, é baseado nos ensinamentos da Regulação Econômica e em diretrizes apontadas pela International Organization of Supreme Audit Institutions (INTOSAI), e leva em conta a caracterização de serviço público imposta àquelas atividades pela Constituição Federal. Aqui, focou-se atenção nos elementos mais diretamente relacionados à competitividade. Percebe-se que a competição não é estimulada pelos regramentos, que há muitas barreiras à entrada nos mercados, que licitações para delegação dos serviços são raras, e que o setor carece de reformas para que os serviços sejam prestados de forma mais eficaz e moderna.
\end{abstract}

\begin{abstract}
This paper shows the results from the application of a proposed model of audit upon the regulations and institutions of the Intercity Coach Transport (TIPO) systems from three Brazilian States and from the National Interstate Coach Transport (TRIP) system. The model shows good regulatory practices and it is based on the lessons from the Economic Regulation and from the guidelines of the INTOSAI. The constitutional characterization of the sector as a public service is also taken into consideration. Here, the attention is more specifically drawn to competitive elements. It is perceived that competition is not stimulated by the regulations, that there are many barriers to the entry of new operators, that competitive tendering processes are rare. Hence, the developed analyses show that reforms are in need, and that the state regulation regarding the TIPO provision has to seek a more efficient and modern pattern.
\end{abstract}

\section{INTRODUÇÃO}

Este artigo aborda aspectos relativos à competitividade na regulamentação do serviço público de transporte rodoviário passageiros. Essa temática tem assento numa questão mais abrangente, e que vem ganhando importância desde os anos 1970, e no Brasil notadamente desde a década de 1990, que é a questão da discussão e da redefinição do relacionamento do Estado com a Sociedade, e de qual papel aquele deve exercer sobre as atividades econômicas, e mais precisamente na provisão dos serviços públicos aos seus cidadãos.

Para ilustrar sua importância na economia nacional, em 2005 o transporte de passageiros por ônibus auferiu, através de 25.046 empresas, que empregaram 616.792 pessoas, 26\% da receita operacional líquida do setor de transportes, que girou em torno de $\mathrm{R} \$$ 101,5 bilhões. Considerando-se dados de empresas com 20 ou mais pessoas ocupadas, a receita operacional líquida do transporte rodoviário regular nãourbano de passageiros ficou em torno dos RS 7,2 bilhões (IBGE, 2007). O artigo ora apresentado é original, resulta de pesquisa de Mestrado e aborda um pro-

${ }^{1}$ Fernando Antonio Oliveira Rolim, Tribunal de Contas do Estado de Pernambuco - TCE/PE; Universidade Federal de Pernambuco, Recife, PE, Brasil. (e-mail: frolim@tce.pe.gov.br).

${ }^{2}$ Anísio Brasileiro, Universidade Federal de Pernambuco, Recife, PE, Brasil. (e-mail: anisio.brasileiro@ufpe.br).

Manuscrito recebido em 26/6/2008 e aprovado para publicação em 6/6/2009. Este artigo é parte de TRANSPORTES, volume XVII, número 1, junho de 2009. ISSN: 1415-7713. blema de alta relevância econômica e social.

No cenário recente, o envolvimento do Estado nas atividades econômicas tem migrado de uma posição de provedor direto dos serviços, para uma função de regulação dos particulares convocados e contratados para o desempenho de atividades públicas (Marshall, 2000; Brasileiro e Aragão, 2000; Moraes, 1997; Mattos et al., 2004), sem, contudo, perder a sua titularidade (Amaral, 2002). O Estado passa, portanto, de uma atitude monopolista e regulamentadora, para uma postura regulatória e fomentadora (Moreira Neto, 2003). Essa modificação na forma da execução dos serviços públicos é coerente com o "caráter cíclico da intervenção estatal na economia, o qual corresponde à natureza cíclica da dinâmica capitalista” (Santos, 2000).

O Brasil tem uma longa tradição em considerar o transporte rodoviário de passageiros como serviço público (cf. Gomide e Martins, 2005), tendo a vigente Constituição Federal (CF/1988) incorporado essa tendência. Devido a essa caracterização, o setor precisa ser submetido à regulação, auditoria e controle públicos. O gerenciamento e a regulação da atividade têm sido conduzidos por instituições rodoviárias ou por entidades de transportes públicos. Recentes reformas têm alterado esse quadro institucional, e muitos estados têm criado agências regulatórias (Brasileiro e Orrico Filho, 2005), que ainda carecem de independência e efetivo poder e prática.

Entretanto, na maioria das situações, o setor ainda não foi adaptado ao arcabouço constitucional vigente. Assim, duas diferentes realidades são percebidas, uma 
de fato e outra formal, esta tentando mostrar que os sistemas funcionam em acordo com as obrigações dos estatutos vigentes, aquela mostrando um vazio entre o que é pretendido pelas leis e o que efetivamente ocorre na prática. Essa dicotomia leva a uma estrutura arcaica, que apresenta muitas falhas, na qual a competição não é uma regra, mas uma exceção. Dessa forma, não há nem uma estrutura de livre mercado, nem uma estrutura competitiva controlada por algum tipo de regulação econômica. Em vez disso, o mercado é composto, em quase sua inteireza, por direitos de operação exclusivos e por fortes barreiras à entrada de novos operadores (Rolim et al., 2007).

Neste artigo são apresentados resultados da aplicação de um modelo de auditagem proposto, no que tange aos aspectos relativos à competitividade, sobre as regulamentações e instituições de três sistemas estaduais de Transporte Intermunicipal Convencional de Passageiros por Ônibus (TIPO), a saber, da Bahia, do Rio de Janeiro e de Santa Catarina, bem como sobre o sistema nacional Transporte Interestadual por Ônibus (TRIP). Originalmente o modelo foi desenvolvido para emprego pelos Tribunais de Contas, mas também pode ser usados por outras instituições envolvidas com o assunto. Ressalta-se que os estudos desenvolvidos excluem as linhas iniciadas e terminadas dentro de uma mesma região metropolitana, bem como do transporte interestadual semi-urbano. Os sistemas foram selecionados porque neles foram observadas auditagens realizadas pelos respectivos Tribunais de Contas (Rolim, 2007).

Na seção 2 será apresentado o arcabouço constitucional brasileiro do transporte rodoviário de passageiros, para em seguida, na seção 3, ser relembrado como o modelo proposto foi construído. Na seção 4 são exibidos os resultados das análises decorrentes da aplicação do modelo no que diz respeito aos aspectos de competitividade sobre os estudos de caso selecionados, após o quê são feitas conclusões e apresentam-se as referências bibliográficas.

\section{ARCABOUÇO CONSTITUCIONAL DO TRANSPORTE RODOVIÁRIO DE PASSAGEIROS}

De acordo com a CF/1988, o gênero transporte rodoviário de passageiros é composto por quatro espécies: internacional (ocorre entre o Brasil e seus vizinhos), interestadual (ocorre entre cidades de diferentes estados), intermunicipal (ocorre entre cidades de um mesmo estado), e distrital (entre municipalidades dentro do Distrito Federal). Institucionalmente, cada um é submetido a certo nível administrativo. Assim, o modo internacional e o interestadual são geridos e regulados por entidades federais (CF/1998, artigo 21, XII, e), o distrital por entidades do Distrito Federal
(CF/1988, artigo 32, $\S 1^{\circ}$ ), e o intermunicipal, seguindo a tradição constitucional, está sob a responsabilidade dos estados (CF/1988, artigo 25, §1 $1^{\circ}$ ).

Porque o TIPO é um serviço público, a Administração Pública detém a titularidade dos serviços e pode executá-los diretamente ou delegá-los a particulares. Neste caso, a delegação tem de obedecer ao artigo 175 da CF/1988, que impõe que todo contrato de delegação de serviço público tem de ser precedido de licitação pública. Citado artigo é disciplinado pela Lei Federal 8.987/1995, que é a primeira lei em toda a história constitucional brasileira a lidar com o tema das delegações dos serviços públicos.

Historicamente, os serviços do TIPO (e de TRIP) vêm sendo operados por empresas privadas, sujeitas à regulação pública, sem subsídios (Rolim e Brasileiro, 2005), em acertos de longa duração, sem que tenha havido uma real disputa de mercado para a obtenção dos direitos de operação das linhas. Na maioria dos casos, os serviços vinham, até o advento da CF/1988, sendo realizados baseados em delegações precárias, que eram renovadas quase que automaticamente e sucessivamente findos os prazos estabelecidos. Após 1988, os contratos continuaram a ser renovados e, após 1995, em muitos estados, foram sendo transformados em concessões, para adequação ao novo ordenamento, entretanto sem a feitura de licitações (Rolim, 2007). Assim sendo, a prestação dos serviços foge à regra de provisão direta estatal que costumava acontecer no Brasil até os anos 1990 na maior parte dos serviços públicos. Apesar disso, todo o novo arcabouço regulamentador a que os demais serviços recentemente delegados precisam se submeter, também ao transporte rodoviário de passageiros deve ser aplicado.

A prestação dos serviços vem passando por vários problemas, a exemplo de queda na demanda transportada e na arrecadação de impostos, elevação de custos, paralisação de boa parte das linhas, falta de atendimento a localidades menos privilegiadas, falta de políticas públicas, deficit de financiamento (Gifoni Neto, 2002), falta de interesse das empresas em melhorar sua eficiência, omissão governamental na regulação de situações que se desviam do modelo de competição perfeita, conflito de interesses entre os diversos níveis administrativos envolvidos (Rolim et al., 2007), entre outros.

A situação reinante é injustificável, e reformas em nível infraconstitucional são indispensáveis. O arcabouço constitucional para essas mudanças já existe, mas é urgente o surgimento de vontade política para colocá-las em prática. É necessário o desenvolvimento de regulamentos que busquem máxima eficiência na provisão dos serviços, bem como ganhos sociais. O vazio entre legislação e realidade precisa ser eliminado, e há certas instituições que podem contribuir nesse 
desafio, a exemplo dos Tribunais de Contas. Essas instituições são responsáveis pelo controle, dito externo, dos gastos públicos e das delegações dos serviços públicos, e podem contribuir com o fortalecimento das agências reguladoras e de outras instituições públicas envolvidas com a gestão dos serviços.

\section{RELEMBRANDO O MODELO}

Devido à caracterização de serviço público, o transporte rodoviário de passageiros precisa ser submetido à regulação, auditoria e controle públicos. Como contribuição para uma melhor gestão pública desses serviços, Rolim e Brasileiro (2006) propuseram um modelo, posteriormente incrementado (Rolim et al., 2007; Rolim, 2007), que sugere boas práticas regulatórias para o TIPO, e tem como propósito inicial ser empregado pelos Tribunais de Contas em auditagens sobre o setor, mas que também pode ser adotado por outras instituições envolvidas na gestão do TIPO.

Como premissa básica, considerou-se a necessidade de abertura do setor à competição, através de procedimentos licitatórios, nos quais critérios de performance operacional fossem incluídos. Essa preocupação se justifica, pois além de constituir imposição constitucional, as licitações poderiam contribuir para uma melhoria dos serviços, por meio de indução de necessidade permanente de busca por melhor eficiência e redução de custos operacionais como condicionantes para que os operadores se mantivessem como delegatários, de tal forma que os usuários fossem os principais beneficiários do processo.

A construção do modelo se deu pela incidência de parâmetros considerados como boas práticas regulató-

Tabela 1. Parâmetros a adotar no Modelo

\begin{tabular}{|c|c|c|c|}
\hline \multirow{2}{*}{$\begin{array}{l}\text { Seções dos Guidelines } \\
\text { da INTOSAI }\end{array}$} & \multicolumn{2}{|r|}{ Guidelines da INTOSAI } & \multirow{2}{*}{ Parâmetros da Regulação Econômica } \\
\hline & $N^{o}$ & Descrição & \\
\hline \multirow{2}{*}{$\begin{array}{c}\text { - Habilidades das } \\
\text { Instituições de } \\
\text { Auditoria } \\
\end{array}$} & 1 & requerimentos de habilidades & - \\
\hline & 2 & adquirindo habilidades & - \\
\hline \multirow{6}{*}{$\begin{array}{l}2 \text { - O Ambiente da } \\
\text { Regulação Econômica }\end{array}$} & 3 & a estrutura regulatória & A - estrutura organizacional \\
\hline & 4 & objetivos, funções e poderes & A - estrutura organizacional \\
\hline & 5 & imparcialidade e integridade & - \\
\hline & 6 & competência técnica & - \\
\hline & 7 & necessidades de informação & $\begin{array}{l}\text { B - acesso a informações da prestação dos } \\
\text { serviços }\end{array}$ \\
\hline & 8 & transparência, responsabilidade e consulta & - \\
\hline \multirow{8}{*}{$\begin{array}{l}3 \text { - O Fornecimento } \\
\text { dos Serviços }\end{array}$} & \multirow[b]{2}{*}{9} & \multirow[b]{2}{*}{ segurança e fornecimento } & C - definição de atribuições \\
\hline & & & $\begin{array}{l}\text { D - direitos dos usuários e forma de controle } \\
\text { social }\end{array}$ \\
\hline & 10 & acesso do consumidor & $\begin{array}{l}\text { D - direitos dos usuários e forma de controle } \\
\text { social }\end{array}$ \\
\hline & 11 & consumidores vulneráveis ao fornecimento & $\begin{array}{l}\text { E - alcance dos serviços a regiões fora do } \\
\text { mercado convencional }\end{array}$ \\
\hline & \multirow[t]{2}{*}{12} & \multirow[t]{2}{*}{ padrões de serviço } & $\begin{array}{l}\text { D - direitos dos usuários e forma de controle } \\
\text { social }\end{array}$ \\
\hline & & & F - forma de controle de quantidade e qualidade \\
\hline & 13 & lidando com reclamações dos consumidores & $\begin{array}{l}\text { D - direitos dos usuários e forma de controle } \\
\text { social }\end{array}$ \\
\hline & 14 & temas ambientais & - \\
\hline \multirow{7}{*}{$\begin{array}{l}4 \text { - O Preço do } \\
\text { Serviço }\end{array}$} & 15 & controle de preços & G - política tarifária e de subsídios \\
\hline & 16 & ligando preço à qualidade & F - Forma de controle de quantidade e qualidade \\
\hline & 17 & encorajando a eficiência do fornecedor & $\begin{array}{l}\text { H - Forma de incentivo à produtividade e à } \\
\text { redução de custos }\end{array}$ \\
\hline & \multirow{2}{*}{18} & \multirow{2}{*}{ custos de financiamento dos fornecedores } & I - forma de remuneração dos fornecedores \\
\hline & & & $\mathrm{J}$ - maneira de definição da tarifa \\
\hline & \multirow{2}{*}{19} & \multirow{2}{*}{ investimento } & C - definição de atribuições \\
\hline & & & L - distribuição dos riscos \\
\hline \multirow{8}{*}{$\begin{array}{l}5 \text { - Desenvolvendo a } \\
\text { Competição }\end{array}$} & 20 & redução de monopólio e de dominação de mercado & $\mathrm{N}$ - estrutura competitiva \\
\hline & \multirow{3}{*}{21} & \multirow{3}{*}{ promoção da escolha do consumidor } & $\begin{array}{l}\text { D - direitos dos usuários e forma de controle } \\
\text { social }\end{array}$ \\
\hline & & & Q - segmentação da oferta \\
\hline & & & R - agrupamento dos serviços \\
\hline & \multirow{4}{*}{22} & \multirow{4}{*}{ combate a práticas anticompetitivas } & $\begin{array}{l}\text { M - barreiras à entrada e formas de acesso ao } \\
\text { mercado }\end{array}$ \\
\hline & & & $\mathrm{N}$ - estrutura competitiva \\
\hline & & & $\begin{array}{l}\text { O - forma de contratação e delegação dos } \\
\text { serviços }\end{array}$ \\
\hline & & & P - prazo de duração dos contratos \\
\hline
\end{tabular}


rias, advindos da Regulação Econômica (coluna à direita da Tabela 1), sobre os guidelines da International Organization of Supreme Audit Institutions (INTOSAI, 2001; Marshall, 2000; Rolim, 2007) para auditagens sobre Regulação Econômica, conforme Tabela 1. Cabe salientar que o modelo não tem a pretensão de esgotar todos os aspectos envolvidos na provisão dos serviços, em absoluto.

Neste artigo, por questões de espaço, resolveu-se focar atenção nos aspectos relativos à competição (seção 5 dos guidelines da INTOSAI). Dessa forma, a parte correspondente do modelo proposto é exibida na Tabela 2. Considera-se que a melhoria de determinado regulamento seria atingida pela alteração de seus elementos caracterizados como inadequados, através da introdução de características tidas como boas, segundo as explicações constantes da Tabela 2. Assim, a boa prática conduz a um regulamento adequado.

\section{APLICAÇÃO DO MODELO AOS CASOS SELECIONADOS}

Essa seção sumariza as análises desenvolvidas sobre os regulamentos e instituições relacionadas ao TIPO dos estados da Bahia, Rio de Janeiro e Santa Catarina, e também ao TRIP. Inicialmente é feita uma descrição de cada um dos sistemas, para em seguida serem feitos comentários acerca dos marcos regulatórios dos qua- tro sistemas. Por fim são mostrados os resultados da incidência do modelo sobre a regulamentação dos quatro estudos de caso.

\subsection{Descrição dos sistemas analisados}

A União dispõe de agência regulatória específica para o TRIP. Trata-se da Agência Nacional de Transportes Terrestres (ANTT) - autarquia vinculada ao Ministério dos Transportes - que é responsável não só pelo planejamento e fiscalização dos serviços, mas também pela sua delegação. O Anuário Estatístico sobre o desempenho do transporte interestadual e internacional de passageiros é elaborado anualmente pela ANTT, e a versão de 2007, contendo como base de dados o ano de 2006, aponta a operação de 222 empresas, com uma frota total de 15.616 ônibus, divididos em 363 linhas de transporte semi-urbano, 2.694 linhas de transporte acima de $75 \mathrm{~km}$, com 71.545 .404 passageiros transportado no modo semi-urbano, e com 65.139.201 passageiros no modo acima de 75km (ANTT, 2007).

Na Bahia a Agência Estadual de Regulação de Serviços Públicos de Energia, Transportes e Comunicações da Bahia (AGERBA) é a agência regulatória para os serviços de TIPO. A agência é instituída sob a forma de autarquia e é vinculada à Secretaria Estadual de Infra-Estrutura, sendo responsável não só pelo planejamento, fiscalização dos serviços, elaboração de normas, análise e homologação dos reajustes e revisões

Tabela 2. Critérios para uma boa regulação

\begin{tabular}{|c|c|c|c|}
\hline $\begin{array}{l}\text { Seções dos } \\
\text { Guidelines }\end{array}$ & $\begin{array}{l}\text { Guideline da } \\
\text { INTOSAI }\end{array}$ & $\begin{array}{l}\text { Parâmetros da Regulação } \\
\text { Econômica }\end{array}$ & A Prática Regulatória Será Considerada Boa ou Adequada se: \\
\hline \multirow{8}{*}{ 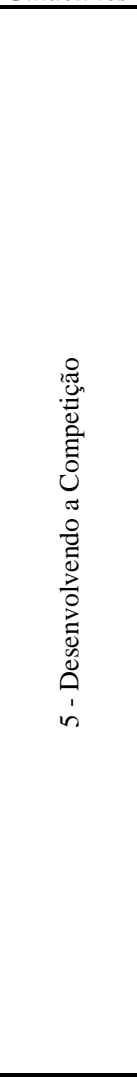 } & $\begin{array}{l}20 \text { - redução de } \\
\text { monopólio e de } \\
\text { dominação de } \\
\text { mercado }\end{array}$ & $\mathrm{N}$ - estrutura competitiva & $\begin{array}{l}\text { houver indução à verificação quanto a práticas anti-competitivas pelo } \\
\text { viés da dominação dos mercados. Nas linhas com mais de uma opera- } \\
\text { dora, deveria haver verificação quanto a eventuais abusos de poder e- } \\
\text { conômico (e.g. truste, cartel, dumping). }\end{array}$ \\
\hline & \multirow{3}{*}{$\begin{array}{l}21 \text { - promoção da } \\
\text { escolha do } \\
\text { consumidor }\end{array}$} & $\begin{array}{l}\text { D - direitos dos usuários e } \\
\text { forma de controle social }\end{array}$ & $\begin{array}{l}\text { os usuários forem esclarecidos sobre os seus direitos e deveres relacio- } \\
\text { nados à prestação dos serviços, sobre as diversas possibilidades de a- } \\
\text { cesso aos serviços, sobre preços, sobre alternativas de fornecedores e } \\
\text { uso dos serviços e como ter acesso a essas possibilidades. }\end{array}$ \\
\hline & & Q - segmentação da oferta & $\begin{array}{l}\text { a oferta for diversificada e não se permitir a formação de monopólios. } \\
\text { Para isso as delegações dos serviços (regulares, suplementares e asso- } \\
\text { ciados) não deveriam ser feitas de forma única. A boa prática corres- } \\
\text { ponderia ao desmembramento vertical. }\end{array}$ \\
\hline & & $\mathrm{R}$ - agrupamento dos serviços & $\begin{array}{l}\text { evitar que um só operador fique responsável por determinada área geo- } \\
\text { gráfica. }\end{array}$ \\
\hline & \multirow{4}{*}{$\begin{array}{l}22 \text { - combate a } \\
\text { práticas } \\
\text { anticompetitivas }\end{array}$} & $\begin{array}{l}\text { M - barreiras à entrada e } \\
\text { formas de acesso ao mercado }\end{array}$ & $\begin{array}{l}\text { Reduzir as barreiras à entrada no mercado e permitir que o maior nú- } \\
\text { mero de potenciais interessados possam se habilitar nas licitações. }\end{array}$ \\
\hline & & $\mathrm{N}$ - estrutura competitiva & $\begin{array}{l}\text { estabelecer a competição para o mercado, resultante de práticas licitató- } \\
\text { rias do tipo competitive tendering. Quando conveniente e possível, po- } \\
\text { deria ser permitida a competição no mercado, através do desmembra- } \\
\text { mento horizontal, com a fragmentação de linhas e horários entre vários } \\
\text { operadores, ao invés de um só. }\end{array}$ \\
\hline & & $\begin{array}{l}\text { O - forma de contratação e } \\
\text { delegação dos serviços }\end{array}$ & $\begin{array}{l}\text { os serviços decorrerem de permissões (e não de concessões, haja vista } \\
\text { as barreiras à entrada no mercado que essas estabelecem), precedidas } \\
\text { de licitações, fundamentadas nas Leis Federais 8.987/1995 e } \\
\text { 9.074/1995, e complementadas, no que couber, pela Lei Federal } \\
\text { 8.666/1993 e suas diversas alterações. }\end{array}$ \\
\hline & & $\begin{array}{l}\text { P - prazo de duração dos } \\
\text { contratos }\end{array}$ & $\begin{array}{l}\text { os ciclos licitatórios se repetirem após prazos contratuais pequenos. A } \\
\text { experiência sueca recomenda prazos entre três e cinco anos, podendo } \\
\text { atingir um máximo de } 7 \text { anos, nesse prazo incluindo-se eventuais pror- } \\
\text { rogações vinculadas a análises de desempenho. A European Commis- } \\
\text { sion (2001) também recomenda prazos de cinco anos para contratos } \\
\text { decorrentes de processos licitatórios. }\end{array}$ \\
\hline
\end{tabular}


de tarifas, mediação de divergências entre usuários e concessionários, mas também pela sua delegação, conforme dispõe a Resolução 027/2001. Salienta-se que a AGERBA foi instituída pela Lei Estadual 7.314/1998. Em 2006, o transporte intermunicipal baiano como um todo registrou a presença de 47 empresas delegatárias dos serviços, que operaram 266 linhas no subsistema estrutural, 316 no subsistema regional, e 51 no subsistema rural (AGERBA, 2006).

O Estado do Rio de Janeiro não dispõe de agência reguladora específica para o TIPO, cuja gestão e regulação são feitas pelo Departamento de Transportes Rodoviários (DETRO) - autarquia vinculada à Secretaria de Estado de Transportes - que controla o setor e, planeja, concede, intervém, permite, autoriza, licencia, fiscaliza, regulamenta e fixa as tarifas, conforme estabelecido pelo Decreto Estadual 3.893/1981. Toda a operação do transporte coletivo intermunicipal é feita por particulares, em um total de 109 empresas que operam 1.090 linhas, utilizando uma frota de 6.167 veículos, sendo 4.920 do tipo urbano, 143 do tipo urbano com ar condicionado, 982 do tipo rodoviário e 122 do tipo rodoviário com ar condicionado, com uma movimentação mensal superior a 52 milhões de passageiros. (Secretaria de Transportes/RJ, 2007).

Em Santa Catarina, embora já exista agência regulatória para o setor - a Agência Reguladora de Serviços Públicos de Santa Catarina (AGESC) - com organização dada pela Lei Estadual 13.533/2005, e com Regimento Interno aprovado pelo Decreto Estadual 3.798/2005, a instituição ainda não desempenha suas funções relativas ao transporte intermunicipal. O setor é regulado pelo Departamento de Transportes e Terminais (DETER) - autarquia vinculada à Secretaria de Estado de Infra-Estrutura - que planeja, executa, fiscaliza, controla, delega, licita, e firma contratos do serviço público de TIPO (Decreto Estadual 12.601/1980). O sistema gerenciado pelo DETER é constituído por 1.023 transportadoras. Destas, 67 operam 961 linhas regulares sob a forma de concessão, e transportam anualmente mais de 85 milhões de passageiros. Demais operadoras fazem serviços de fretamento e viagens especiais. A frota de veículos cadastrados é de 4.997 ônibus (DETER/SC, 2007).

\subsection{Regulamentos dos transportes rodoviários dos sistemas selecionados}

Na União, o Decreto 2.521/1998 é o marco regulatório e foi feito sem que houvesse lei anterior que previsse a sua existência. Esse fato tem acarretado questionamentos sobre sua constitucionalidade (TCU, 2005), haja vista ter sido emitido como decreto autônomo, apesar de não o ser, pois não corresponde a nenhuma das hipóteses permitidas pelos incisos IV e VI da CF/1988. Além disso, há de ser citado que a Lei
10.233/2001, que criou a ANTT, é posterior ao Decreto $2.521 / 1998$, que dispõe sobre o transporte rodoviário interestadual e internacional, e, por conta disso, há competências dadas à Agência que outrora eram conferidas ao Ministério dos Transportes, sem que tenha havido uma devida harmonização jurídica dessas atribuições.

A Resolução AGERBA 27/2007 corresponde ao marco regulatório baiano e é posterior às leis 6.654/1994 e 7.314/1998 que prevêem a sua existência. Não é, portanto, decreto autônomo, como sói ocorrer com o Decreto 2.521/1998 da União.

No Rio de Janeiro, o marco regulatório (Decreto Estadual 3.893/1981, com alterações posteriores) foi feito sem que houvesse lei anterior que previsse a sua existência, o que pode caracterizá-lo como decreto autônomo, da mesma forma que ocorre com o Decreto 2.521/1998 da União. O marco tem por fundamento outro decreto (o antigo Decreto-Lei 276/1975).

Em Santa Catarina, o marco regulatório (Decreto 12.601/1980, com alterações posteriores) foi feito em atendimento à determinação de lei anterior que previu a sua existência (Lei 5.684/1980, artigo 19).

\subsection{Resultados da incidência do modelo sobre a regulamentação dos estudos de caso}

A Tabela 3 apresenta resultados concisos das análises comparativas feitas nos regulamentos dos quatro sistemas selecionados. Como o modelo contém 16 guidelines, e 25 parâmetros esclarecedores, não é viável discutir cada resultado das análises feitas, por limitação de espaço. Assim, decidiu-se focar nos aspectos mais relacionados à competição, i.e., aos guidelines 20 (redução de monopólio e de dominação de mercado), 21 (promoção da escolha do consumidor), e 22 (combate a práticas anticompetitivas).

Tabela 3. Análise comparativa resumida dos regulamentos dos casos selecionados

\begin{tabular}{|c|c|c|c|c|c|}
\hline \multirow{2}{*}{$\begin{array}{l}\text { Guidelines da } \\
\text { INTOSAI }\end{array}$} & \multirow{2}{*}{ 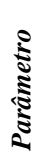 } & \multirow{2}{*}{ União } & \multicolumn{3}{|c|}{ Estados selecionados } \\
\hline & & & $B A$ & $\boldsymbol{R J}$ & $S C$ \\
\hline $\begin{array}{l}20 \text { - redução de } \\
\text { monopólio e de } \\
\text { dominação de } \\
\text { mercado }\end{array}$ & $\mathrm{N}$ & $\checkmark *$ & $\mathbf{x} *$ & $x *$ & $x$ \\
\hline \multirow{3}{*}{$\begin{array}{l}21 \text { - promoção da } \\
\text { escolha do } \\
\text { consumidor }\end{array}$} & D & $\checkmark *$ & $\checkmark *$ & $x *$ & $x *$ \\
\hline & $\mathrm{Q}$ & $x$ & $x$ & $x$ & $x$ \\
\hline & $\mathrm{R}$ & $x$ & $x$ & $x$ & $x *$ \\
\hline \multirow{4}{*}{$\begin{array}{l}22 \text { - combate a } \\
\text { práticas } \\
\text { anticompetitivas }\end{array}$} & $\mathrm{M}$ & $\checkmark *$ & $x$ & $x$ & $x *$ \\
\hline & $\mathrm{N}$ & $x *$ & $x$ & $x *$ & $x *$ \\
\hline & $\mathrm{O}$ & $\checkmark *$ & $x *$ & $x *$ & $x *$ \\
\hline & $\mathrm{P}$ & $x *$ & $x *$ & $\bar{x}$ & $x *$ \\
\hline
\end{tabular}

Legenda: $\checkmark$ : boa prática; $\mathbf{x}$ : prática inadequada.

Fonte: Rolim (2007). 
Na Tabela 3 há parâmetros para os quais são indicadas ambas as práticas, boa e inadequada. Essas situações estão assinaladas com um asterisco (*), e são decorrentes dos regulamentos analisados mostrarem alguns bons aspectos baseados nas disposições da Tabela 2, mesmo quando não inteiramente em acordo com os critérios para uma boa regulação. Entretanto, foi decidido destacar, nos comentários adiante, apenas as práticas que são mais significativas para cada parâmetro. Isso definirá como o parâmetro foi considerado, de acordo com o modelo proposto, se bom ou inadequado, após o balanço entre os prós e contras de seu comportamento em relação aos critérios do modelo.

\subsubsection{Guideline 20: redução de monopólio e de dominação de mercado}

\subsubsection{Parâmetro N: estrutura competitiva}

Na União o indicativo de boa prática decorre: a) da imposição ao Poder Concedente para provocar a Secretaria Nacional de Direito Econômico sempre que perceba atos ilícitos previstos nas leis que regulam a repressão ao abuso do poder econômico e a defesa da concorrência; b) da vedação à exploração de serviços numa mesma linha por transportadoras que mantenham vínculo de interdependência econômica (para que a prática regulatória fosse aperfeiçoada, esse impedimento poderia ser ampliado para além de uma só linha, abrangendo uma base territorial mais ampla, para evitar concentração de mercado em linhas adjacentes e estimular a competição); c) da permissão em praticar tarifas promocionais, desde que não impliquem quaisquer formas de abuso do poder econômico ou que não agridam as normas de defesa da concorrência; d) do estabelecimento da penalidade de declaração de inidoneidade da transportadora, e da conseqüente caducidade da permissão, em caso de prática de abuso do poder econômico ou infração às normas de defesa da concorrência; e) da incorporação, entre os objetivos da ANTT, do impedimento de situações que configurem competição imperfeita ou infração da ordem econômica; f) da obrigação imposta à ANTT, ao tomar conhecimento de fato que configure ou possa configurar infração da ordem econômica, de comunicá-lo ao Conselho Administrativo de Defesa Econômica (CADE), à Secretaria de Direito Econômico do Ministério da Justiça ou à Secretaria de Acompanhamento Econômico do Ministério da Fazenda, conforme o caso.

Na Bahia, apesar da regulamentação estipular que na exploração dos serviços observar-se-ão as leis que regulam a repressão do abuso ao poder econômico e à defesa da concorrência, inclusive a prática de preços abaixo dos custos de produção, não há dispositivos que assegurem a verificação sistemática de eventuais práticas anticompetitivas, através de análise sistêmica dos contratados e de seu inter-relacionamento societário. Cite-se, entretanto, que na Bahia também é estabelecida a penalidade de declaração de inidoneidade da transportadora em caso de crimes contra a economia popular, e que eventual declaração de inidoneidade importará caducidade da delegação. Acrescenta-se que o regulamento não apresenta dispositivos que vedem a exploração de serviços numa mesma linha, nem numa base territorial mais ampla, por transportadoras que mantenham vínculo de interdependência econômica.

No Rio de Janeiro e em Santa Catarina os regulamentos não estipulam que na exploração dos serviços observar-se-ão as leis que regulam a repressão do abuso ao poder econômico e à defesa da concorrência, inclusive a prática de preços abaixo dos custos de produção, e não há dispositivos que assegurem a verificação sistemática de eventuais práticas anticompetitivas, através de análise sistêmica dos contratados e de seu inter-relacionamento societário. Também não se estabelece que seja declarada inidoneidade da transportadora em caso de prática de abuso do poder econômico ou infração às normas de defesa da concorrência. Ressalte-se que no Rio de Janeiro é vedada a exploração de serviços numa mesma ligação pelo mesmo itinerário por transportadoras que mantenham vínculo de interdependência econômica (salienta-se que, assim como na União, o impedimento poderia ser ampliado para além de uma só linha, abrangendo uma base territorial mais ampla). Em Santa Catarina não há dispositivos que façam referência a essa vedação.

\subsubsection{Guideline 21: promoção da escolha do consumidor}

\subsubsection{Parâmetro D: direitos dos usuários e forma de controle social}

Na União e na Bahia as regulamentações trazem capítulo específico que trata dos direitos e deveres dos usuários, o que é bom para a qualidade regulatória. É necessário, contudo, que esses direitos sejam explicitamente e constantemente divulgados, através de campanhas de divulgação permanentes. Constitui boa regulamentação a possibilidade de qualquer cidadão ter acesso a informações e documentos relativos às licitações e às delegações, bem como a garantia do recebimento de informações corretas sobre as condições dos serviços. Também constitui boa prática a obrigação à permissionária de afixar em lugar visível, e de fácil acesso ao usuário, no local de venda das passagens e nos terminais de embarque e desembarque, os direitos e deveres dos usuários.

Na Bahia cabe citar uma boa iniciativa da AGERBA que é o desenvolvimento do "Projeto Crescendo: Regulação e Cidadania Ativa”, através do qual são divulgados os direitos e deveres dos usuários do 
sistema de transporte intermunicipal nas escolas baianas do ensino médio e fundamental, através da distribuição de material didático e de atividades pedagógicas (AGERBA, 2007). Isso pode contribuir para uma cultura de reconhecimento e exercício de direitos e deveres por parte dos usuários, atuais e futuros, do TIPO no estado. Também cabe ser mencionada a elaboração, pela AGERBA, de cartilhas informativas contendo os direitos e deveres dos usuários, bem como informações acerca da gratuidade e concessão de desconto para os maiores de sessenta anos de idade, a serem distribuídas junto à população.

No Rio de Janeiro e em Santa Catarina os regulamentos não trazem capítulo específico que trate dos direitos e deveres dos usuários, o que é ruim para a qualidade regulatória. Seria necessário, inclusive, que esses direitos fossem explicitamente e constantemente divulgados, através de campanhas de divulgação permanentes. Cite-se, entretanto, que ambos os regulamentos impõem que a transportadora fixe em lugar visível, nos terminais e interior dos veículos, os certificados de concessão, permissão ou autorização, conforme o caso, informando as características do serviço oferecido. Além disso, no Rio de Janeiro os bilhetes de passagem devem mencionar a possibilidade de devolução da importância paga, em caso de desistência da viagem por parte do usuário, e o valor do troco máximo deve ser transcrito nos locais de venda das passagens e no interior dos veículos. Na publicidade das transportadoras devem ser evitados expressões ou artifícios que induzam o público a erros sobre as características dos serviços. Em Santa Catarina deverão ser expostas em lugar de fácil visualização, no interior dos veículos e nas agências, as coberturas e importâncias dos seguros facultativos de acidentes pessoais, que serão feitos por conta dos interessados, e se impõe que seja informado no verso dos bilhetes das passagens que os passageiros, vítimas de acidentes, têm direito a indenizações.

Não há disposições, ou regras específicas, nos quatro estudos de caso, acerca da necessidade de divulgação das diversas possibilidades de acesso aos serviços, sobre preços, sobre alternativas de fornecedores e uso dos serviços e como ter acesso a essas possibilidades.

Acresça-se que, se as quatro regulamentações estipulassem a necessidade de divulgação aos passageiros das situações que podem resultar em multa às transportadoras, poder-se-ia ter uma boa contribuição para uma melhor prestação dos serviços.

\subsubsection{Parâmetro Q: segmentação da oferta}

As regulamentações estudadas não trazem instruções no sentido de evitar a contratação de forma única dos serviços envolvidos no segmento do TIPO, e de estimular a ampliação do leque de fornecedores, ou de ampliar a segmentação da oferta, ou de estímulo ao desmembramento vertical, o que seria importante na medida em que estimularia a competição. As únicas disposições que de alguma forma tocam esse parâmetro dizem respeito, na União, à proibição de uma mesma linha ser explorada por operadoras com vínculo de interdependência econômica e, no Rio de Janeiro, à vedação da exploração de serviços numa mesma ligação pelo mesmo itinerário por transportadoras que mantenham vínculo de interdependência econômica.

\subsubsection{Parâmetro R: agrupamento dos serviços}

Os regulamentos analisados não exibem instruções no sentido de evitar o domínio de uma região geográfica por uma mesma operadora. As únicas disposições que de alguma forma tocam esse parâmetro dizem respeito, na União, à proibição de uma mesma linha ser explorada por operadoras com vínculo de interdependência econômica e, no Rio de Janeiro, à vedação da exploração de serviços numa mesma ligação pelo mesmo itinerário por transportadoras que mantenham vínculo de interdependência econômica. Em Santa Catarina, salienta-se, é disposto que não será permitida a celebração de contratos ou ajustes de qualquer natureza, entre transportadoras, que objetivem limitação de área ou região de exploração dos serviços, inclusive sob pena de declaração de inidoneidade.

\subsubsection{Guideline 22: combate a práticas anticompetitivas}

\subsubsection{Parâmetro $M$ : barreiras à entrada e formas de acesso ao mercado}

A Lei Federal 8.987/1995 adotou duas espécies de delegação - concessões e permissões - e a diferença entre elas se assenta nos requerimentos para adoção de uma ou outra, as primeiras sendo mais exigentes que as últimas. Por exemplo, a modalidade concessão só admite que pessoas jurídicas, isoladas ou consorciadas, participem das licitações, excluindo, portanto, a possibilidade de pessoas físicas licitarem. Ambos os modos são formalizados via contrato, porém se o poder público perceber a necessidade de extinção dos serviços antes do advento contratual (e.g. em decorrência de má conduta do operador ou mau fornecimento do serviço, ou até mesmo por razões de interesse público) nas permissões o procedimento é mais simples, e as compensações aos particulares menores.

Ao se analisar a Tabela 3, pode-se observar que a boa prática regulatória foi apontada apenas para a União. Isso se deve ao fato do sistema federal ser o único, dentre os analisados, no qual a permissão é a modalidade de delegação adotada. Entretanto, o Decreto 2.521/1998 restringiu a permissão apenas à pessoa jurídica, criando assim definição diversa da instituída pela Lei Federal 8.987/1995. Apesar disso, manteve- 
se a categorização da prática da União como adequada, haja vista aqui ser entendido que, a despeito do regramento contido no Decreto, as disposições da Lei Federal lhes são superiores e devem e podem ser seguidas.

Os regulamentos dos três estados impõem a concessão como regra geral para a maioria de suas rotas e, por isso, as pessoas físicas são excluídas de operarem nos sistemas e, como conseqüência, barreiras à entrada de novos operadores são estabelecidas. Além de outras implicações, isso significa a perda de oportunidades em enfrentar e solucionar o problema do fornecimento dos serviços a consumidores vulneráveis (e.g. locais com pouca demanda ou de difícil acesso). Além dessa, outras barreiras têm sido impostas pelos regulamentos.

Na Bahia a regulamentação: a) exige que os potenciais entrantes no sistema possuam no mínimo três veículos em acordo com as especificações da AGERBA e capital integralizado mínimo igual ao valor de dois veículos novos; b) estabelece como critério definidor da melhor proposta na licitação a tradição do concorrente em prover serviços similares e a extensão de rotas que a empresa já opera quando da licitação; c) permite que outros fatores, além do valor proposto para a tarifa, definam quem será o vencedor das licitações, tais como capacidade financeira e administrativa da empresa, valor patrimonial, tamanho da frota e das instalações, tradição dos serviços e extensão do número de linhas que a empresa já opera.

$\mathrm{O}$ Rio de Janeiro requer que os potenciais entrantes no sistema tenham objetivos exclusivos de transporte em determinadas categorias, quais sejam, geral, especial, a frete ou transporte privado, de transporte escolar ou social. Dessa forma, uma transportadora que execute uma das modalidades fica impedida de realizar quaisquer das outras três, o que é uma forte barreira.

A regulamentação do Estado de Santa Catarina: a) estabelece que nas licitações, sob as mesmas condições, empresas que já operam no sistema terão preferência diante de novos interessados; b) concede pontuação adicional, no julgamento das licitações dos itinerários a delegar, ao concorrente que já seja concessionário ou permissionário do sistema, ou ao que perderia parcela do mercado com a licitação, ou ao que tenha sua sede localizada em terminais das linhas a licitar; c) dispõe como critério de desempate dos certames privilégio à concorrente que possuir sede no próprio Estado de Santa Catarina, ou à que já vir explorando através de permissão linha que esteja em disputa, ou à que percorra a maior extensão da linha em concorrência com seção de linha que já lhe tenha sido concedida ou permitida anteriormente; d) exige que os interessados em operar no sistema se registrem como transportadoras e comprovem capital registrado mínimo de 70.000 ufir, além de propriedade mínima de dois veículos não alienados, bem como integralização mínima de 50\% do capital registrado.

Convém mencionar que, a despeito de se ter caracterizado o regulamento da União como de boa prática, pela adoção das permissões como regra, convém chamar atenção para uma barreira à entrada que não só ele apresenta, mas também os outros sistemas analisados, que é a possibilidade de se adotar como critério definidor do vencedor da licitação outro que não o menor valor da tarifa a ser cobrada do usuário. Quando se permite que a maior oferta de pagamento pela delegação seja adotada como critério, ainda que em combinação com o menor valor da tarifa, se está a beneficiar empresas mais bem estruturadas diante de firmas menores. Isso ocorre por conta da necessidade do proponente ofertar um valor alto pela outorga para ter alguma chance de vitória. Entretanto, nem sempre todos interessados podem arcar com esse investimento inicial, que pode ser bastante significativo. Cite-se, inclusive, que os editais podem estabelecer valores mínimos aceitáveis para a outorga, e muitos potenciais interessados nos serviços podem desistir de licitar por não poderem eventualmente arcar com esse custo. Dessa forma, um edital de licitação, ao incluir como critério de julgamento a maior oferta pela outorga, está erguendo barreiras à competição para o mercado.

\subsubsection{Parâmetro $N$ : estrutura competitiva}

Em relação à competição para o mercado, embora a regulamentação da União estabeleça a necessidade de prévia licitação, não acerta no estabelecimento dos critérios definidores das melhores propostas nos certames. Essa inadequação ocorre em virtude da regulamentação: a) admitir que apenas a melhor oferta de pagamento pela outorga, após a qualificação de propostas técnicas, possa ser o critério definidor da proposta mais vantajosa; b) permitir que se conjugue o critério da alínea “a” anterior com o menor valor da tarifa pública, como critério definidor da licitação; c) afirmar que a combinação da alínea "b” anterior deverá ser adotada como regra; d) permitir que o critério de definição de menor valor da tarifa possa ser empregado apenas em caráter excepcional, atendido o interesse público, e mediante decisão fundamentada que justifique as razões de conveniência e oportunidade.

Dessa forma, o regulamento trata como exceção aquela que seria a forma mais adequada de escolha do vitorioso em uma licitação para esse tipo de serviço, ou seja, o menor valor da tarifa a ser cobrado do usuário. Isso vai totalmente de encontro ao estipulado pelo artigo 11, IV, da Lei 10.233/2001, que estabelece ser princípio norteador da operação dos transportes terrestres a garantia, sempre que possível, de que os usuá- 
rios paguem pelos custos dos serviços prestados em regime de eficiência.

Entretanto, na prática a definição na União termina sendo dada pelo menor valor da tarifa, em virtude da ANTT, em decorrência dos trabalhos de auditoria do Tribunal de Contas da União (TCU) e do Acórdão 865/2003 do TCU, ter fixado um valor simbólico de $\mathrm{R} \$ 1,00$ para o valor a ser pago pela outorga.

No que diz respeito aos critérios definidores dos vencedores nas licitações, os marcos regulatórios da Bahia, do Rio de Janeiro e de Santa Catarina silenciam e transferem aos editais as suas definições, o que na prática permite a adoção de quaisquer dos critérios gerais estabelecidos na Lei Federal 8.987/1995, ainda que inadequados ao caso do TIPO, como é o maior valor da oferta. No Rio de Janeiro, apesar de ser estatuída a necessidade de prévia licitação, a competição pelo mercado também é prejudicada, haja vista ser o DETRO quem fixa a tarifa, o que desestimula a competição, pois não permite que os contratados busquem atrair maior número de usuários através de sua política de preços. Às operadoras cabe apenas executar os serviços pelas tarifas que o DETRO fixa.

Cabe também citar que o critério de maior valor por outorga para a determinação do vencedor das licitações, que pode ser empregado em quaisquer dos sistemas analisados, traz também outra inadequação, além das já comentadas em 4.3.3.1., que é a possibilidade de transferência do valor da outorga para o preço da tarifa, o que compromete a modicidade tarifária, desestimula a competição pelo mercado, e termina por prejudicar o usuário.

Quanto à competição no mercado, na União as permissões não têm caráter de exclusividade, o que é boa prática, e também o é a permissão dada a uma operadora, em decorrência da entrada de uma concorrente na linha por ela operada, em adaptar-se ao novo cenário, inclusive com redução da frota, freqüências mínimas e tarifas contratuais. Isso pode estimular a competitividade e a modicidade tarifária em prol do usuário. Também convém destacar a explicitação na regulamentação federal de que as normas expedidas pela ANTT deverão visar a que os instrumentos de permissão sejam precedidos de licitação pública e celebrados em cumprimento ao princípio da livre concorrência entre os capacitados para o exercício das delegações.

$\mathrm{Na}$ Bahia, o marco regulatório não traz instruções no sentido de estímulo à competição no mercado, com desmembramento horizontal e fragmentação de linhas e horários. No Rio de Janeiro e em Santa Catarina é prevista a possibilidade de existência de mais de uma transportadora numa mesma ligação, e o estabelecimento, nesses casos, de freqüências que visem a disciplinar a distribuição de horários, o que constitui uma boa prática.
Na Bahia e em Santa Catarina a possibilidade de alteração de itinerário e de encurtamento ou prolongamento de linhas, apenas nos casos em que não seja ameaçado o equilíbrio econômico-financeiro dos serviços de outras transportadoras, desestimula, e até mesmo impede, a competição, na medida em que garante privilégios a transportadoras que já operam em determinadas linhas, e não as submete à concorrência no mercado e a pressões competitivas. Esse dispositivo pode ter como finalidade, através de aparente proteção a contratos vigentes, garantir privilégios e reserva de mercado. Também é passível de crítica a impossibilidade, tanto no Rio de Janeiro quanto em Santa Catarina, de concessão de descontos, por parte das transportadoras, que resultem em concorrência ruinosa ou que comprometam a estabilidade econômica da exploração de outras transportadoras, porquanto essas restrições não resultam em estímulo à competitividade.

Em resumo, e ao extrapolar-se a análise dos regulamentos, e levarem-se em conta também dados empíricos dos quatro sistemas selecionados, obtidos de editais de licitações já realizadas, observa-se que a competição pelo mercado não tem sido uma tônica. Isso se deve tanto pela adoção, como critério definidor do vencedor da disputa, não do menor valor da tarifa ofertada, mas do maior valor de pagamento pela outorga, ainda que em combinação com o menor valor da tarifa, quanto pela falta de licitações, como discutido adiante na subseção que trata da forma de contratação e delegação dos serviços. A competição no mercado, apesar dos instrumentos legais que prevêem seu estabelecimento, é rara de ocorrer, haja vista a pequena quantidade de linhas em que mais de um contratado opera (cf. TCU, 2005).

\subsubsection{Parâmetro O: forma de contratação e delegação dos serviços}

Como já mencionado, o artigo 175 da CF/1988 impõe que toda delegação de serviço público deve ser precedida por um processo licitatório público. A regulamentação dos três estados analisados obedece a esse preceito no que diz respeito às concessões, bem como a legislação da União no que toca as permissões. Entretanto, os regulamentos estaduais não respeitam o princípio constitucional ao lidarem com as permissões, em virtude de afrouxamento no requerimento de prévia licitação. Disso resultam delegações diretas aos operadores, sem que haja submissão a uma real competição para entrada no mercado, o que fere a Constituição Federal e as leis nacionais de delegações de serviço público e de licitações e contratos administrativos.

Em Santa Catarina a regulamentação estadual cria prática inadequada, por conta da instituição do procedimento de edital de consultas para as permissões, e 
das suas formalizações mediante termo de compromisso, e não contrato de adesão. Isso agride frontalmente os dispositivos da Lei Federal 8.987/1995 (especialmente pelo que dispõem os seus artigos $2^{\circ}$, IV, caput do $6^{\circ}$, 18, XVI, 40 caput e parágrafo único). Ressalte-se que a lei federal não estabelece essa possibilidade, mas sim a prévia licitação para as delegações via permissão.

Também cabe citar que no Rio de Janeiro há a possibilidade de que se realizem autorizações para linhas terciárias - e isso implica não realização de licitação que terão validade até que se realizem as devidas concorrências. O problema é que o regulamento não estabelece prazo para a feitura dessas licitações e a autorização pode servir para, efetivamente, perpetuar a delegação dessas linhas terciárias e, assim, burlar a necessidade constitucional de prévia licitação a quaisquer delegações de serviços públicos.

Outro problema detectado nas quatro regulamentações analisadas é a possibilidade de transferência das concessões e das permissões de operadores já estabelecidos para outras companhias, sem que haja prévia licitação. Além de mascarar a efetiva intenção de evitar competição, essa prática também fere o princípio constitucional de necessidade de prévia licitação a qualquer nova contratação de serviço público junto a particulares.

Os regulamentos analisados também não indicam que é necessário que os editais das licitações prevejam que, em caso de realização de transferências de controles acionários, a manutenção da delegação dos serviços ficaria condicionada à posterior aprovação pelo poder concedente.

Além de diminuir as barreiras de entrada nos sistemas, conforme mencionado, outro aspecto positivo em se instituir a permissão como modalidade para a delegação dos serviços é o seu caráter de precariedade e a revogabilidade unilateral do contrato dela resultante pelo Poder Concedente. Assim, em caso de extinção dos contratos de adesão, por encampação, ao particular não caberia indenização por perdas e danos, ou por lucros cessantes, mas apenas indenização de eventuais parcelas dos investimentos vinculados a bens reversíveis, ainda não amortizados ou depreciados, que tivessem sido realizados com o objetivo de garantir a continuidade e atualidade do serviço concedido.

Nesse sentido, cabe também lembrar entendimento similar de di Pietro (1999) quanto ao não cabimento de indenizações, haja vista o caráter de precariedade das permissões. Por conta dessa permanente pressão que a Administração pode exercer sobre os particulares, em nome do interesse público, a adoção da permissão pode também contribuir para conferir uma maior capacidade ao Poder Público em exigir que o permissionário cumpra os serviços conforme as espe- cificações que deveriam constar de cada contrato de serviço de transporte rodoviário por ônibus.

Convém citar que a indenização de eventuais parcelas dos investimentos vinculados a bens reversíveis, ainda não amortizados ou depreciados, em se tratando de serviços de transporte de passageiros por ônibus, praticamente não corresponderia a valores significativos, haja vista a quase não existência de bens reversíveis na atividade. Os veículos são de propriedade dos próprios operadores e com eles permanecem após a extinção dos contratos. Em caso de não existência de outros serviços em que as empresas pudessem alocar os veículos do contrato extinto, esses bens poderiam ser vendidos a terceiros, haja vista o mercado nacional de veículos usados não ser desprezível. O raciocínio de cabimento de indenização apenas pelos valores dos bens reversíveis é justificado pela análise sistêmica do artigo $2^{\circ}$, IV, do artigo 35, II, do artigo 36, do artigo 37, e do artigo 40, caput e parágrafo único, todos da Lei Federal 8.987/1995.

Em adição aos comentários anteriores, ao extrapolar-se a análise dos regulamentos, e levarem-se em conta também dados empíricos dos quatro sistemas selecionados, constata-se que a maior parte dos contratos vigentes não teve origens em licitações, mormente aqueles oriundos do regime constitucional anterior a 1988. Historicamente os serviços foram sendo delegados a particulares, quer através de autorizações quer via permissões, sem disputas efetivas pelo mercado e, após a CF/1988 e a promulgação das Constituições Estaduais, aquelas antigas delegações foram transformadas em permissões ou concessões, os contratos adaptados, e os prazos contratuais renovados. Essa é uma das principais causas do pequeno número de licitações feitas após a CF/1988 para a substituição daqueles contratos. Salienta-se que já se tentaram viabilizar alguns certames e outros já ocorreram após 1988, entretanto geralmente correspondem a novas linhas, e não àquelas que já existiam antes da vigência da atual Constituição.

Diante da grande quantidade de linhas que cada sistema possui, pode-se afirmar que o número de licitações feitas é irrisório. A seguir, mostra-se, para cada caso analisado, como os antigos contratos vêm, através de artifícios normativos, sendo prorrogados, sem submissão a licitações.

Na União, os contratos de todas as linhas antigas de TRIP, em operação desde antes da CF/1988, só deveriam se extinguir em 2008. Essa data limite foi inicialmente estabelecida pelo artigo 94 do já revogado Decreto Federal 952/1993, que manteve os serviços, a partir de sua data, por 15 anos prorrogável por igual período, e posteriormente pelo artigo 98 do Decreto Federal 2.521/1998 - editado já após a Lei Federal 8.987/1995 - que manteve os serviços, sem caráter de 
exclusividade, pelo prazo improrrogável de quinze anos, contados de 7 de outubro de 1993 (data de publicação do revogado Decreto 952/1993). Até o momento, entretanto, não foram feitas licitações para regularização dessas situações.

Na Bahia, o marco regulatório do TIPO, em seu artigo 125 , estabeleceu que as permissões que estivessem em vigor por prazo indeterminado permaneceriam válidas pelo período necessário à realização dos levantamentos e avaliações indispensáveis à organização das licitações que precederiam a outorga das concessões que as substituiriam, obedecido o prazo mínimo de 2 anos - dado pelo artigo 42, § $2^{\circ}$, da Lei Federal 8.987/1995, e prazo máximo de 8 anos, contados a partir de 27 de junho de 1995, ou a juízo do poder concedente (Resolução AGERBA 27/2001). Assim, de certa forma não se fixou um prazo mínimo para que licitações que renovassem os contratos das linhas antigas fossem feitas.

No Rio de Janeiro, a Lei Estadual 2.831/1997 prorrogou as permissões até então vigentes, em mais 15 anos, o que fez com que os contratos fossem estendidos até 2012. Além disso, a citada lei possibilita que haja mais 15 anos de prorrogação, o que levaria os contratos até 2027.

Em Santa Catarina ainda não houve licitações para as linhas antigas - existentes antes da CF/1988 - haja vista seus contratos terem sido prorrogados pela Constituição do Estado até 2001 e, após isso, a Lei 10.824/1998 os ter prorrogado novamente, até 2011. Só houve licitação para linha nova, ainda assim dentro de Região Metropolitana de Criciúma.

Da observação dos conjuntos normativos dos quatro sistemas verifica-se que houve um lapso temporal entre a CF/1988 e os regulamentos que posteriormente vieram a dispor sobre a longevidade dos contratos das linhas antigas. Além disso, quando esses regramentos foram incorporados aos respectivos ordenamentos legais, vieram carregados de inadequações regulatórias, haja vista terem expandido, e em muito, prazos contratuais que não tinham razão de se sustentarem.

Em suma, por causa das legislações mencionadas, nem no TIPO nem no TRIP até agora se fizeram licitações para linhas antigas, só para novas linhas. Além disso, cabe mencionar o elevado número de linhas em operação por conta de medidas liminares judiciais (TCU, 2005), que terminam tendo seus efeitos prolongados à espera de solução definitiva, sem terem que passar por procedimentos licitatórios.

\subsubsection{Parâmetro P: prazo de duração dos contratos}

Os prazos de duração dos contratos têm consistido em uma das maiores barreiras à realização de licitações públicas em todo o país. Ao alegarem respeito a antigos contratos, estabelecidos anteriormente à atual
CF/1988 e à sua legislação infraconstitucional (Lei Federal 8.987/1995 e demais regulamentos federais e estaduais), e que, na maior parte das vezes, nunca foram precedidos de licitação, empresas que já operam os sistemas têm sido perpetuadas em suas rotas sem serem submetidas a testes reais de mercado e, por conseguinte, a uma real competição.

Além disso, mesmo quando os prazos contratuais vigentes se esgotam, muito poucos procedimentos licitatórios têm sido levados a termo, seja pela omissão governamental em pôr o setor em acordo com a regulamentação pós CF/1988, ou devido à eventual colusão entre operadores ao recusarem em participar em licitações lançadas na praça. A ausência de licitações tem feito com que os contratos sejam automaticamente renovados, o que tem comprometido seriamente a competitividade no setor e favorecido as empresas que já operam nos sistemas.

Há que ser mencionado que algumas disputas têm sido realizadas em acordo com os regulamentos pós CF/1988. Mas, mesmo nesses casos, os novos prazos contratuais adotados não podem ser considerados como uma prática regulatória adequada, dadas suas longevidades. Os diversos regulamentos não determinam que os prazos contratuais devam ser estabelecidos após o desenvolvimento de estudos de viabilidade econômica e financeira. Em vez disso, os regramentos analisados impõem prazos que parecem muito longos, em que renovações são possíveis, sem que para isso tenham os operadores que serem submetidos a novos testes de mercado (licitações) ou que tenham de cumprir indicadores de desempenho como garantia de manutenção dos contratos. A Tabela 4 mostra os prazos adotados por cada regulamentação estudada.

Salienta-se que os prazos de 10 anos no Rio de Ja-

Tabela 4. Prazos contratuais adotados em cada regulamentação

\begin{tabular}{lcccc}
\hline \multirow{2}{*}{ Contrato } & União & \multicolumn{3}{c}{$\begin{array}{c}\text { Estados Analisados } \\
\text { (concessões) }\end{array}$} \\
\cline { 3 - 5 } & (permissões) & $\boldsymbol{B A}$ & $\boldsymbol{R J}$ & $\boldsymbol{S C}$ \\
\hline Inicial & 15 anos & 10 anos & 10 anos & 10 anos \\
\hline Renovação & não permitida & 10 anos & 10 anos & 10 anos \\
\hline Fonte: Rolim (2007). & & &
\end{tabular}

neiro referem-se às disposições do marco regulatório do TIPO. Convém lembrar que, a despeito desse regulamento, a Lei Estadual 2.831/1997 determinou que os contratos delegados de prestação de serviços públicos fossem prorrogados, contados da promulgação da lei, em 15 anos, com possibilidade de nova prorrogação em mais 15 anos.

\section{CONCLUSÕES}

O modelo proposto não tem a pretensão de esgotar to- 
dos os aspectos da Regulação Econômica do TIPO. Em vez disso, corresponde a uma tentativa de contribuir para uma melhor gestão de um setor que não tem tido a devida atenção das autoridades públicas (Gifoni Neto, 2002), nem tem sido submetido a maiores estudos acadêmicos. Deve ser reforçado que, apesar de direcionada para os trabalhos dos Tribunais de Contas, a proposta e suas diretrizes podem também ser empregadas por outras instituições envolvidas com a matéria. Os estudos desenvolvidos procuraram adicionar os ensinamentos da Regulação Econômica às recomendações da INTOSAI.

Evidencia-se a necessidade de abertura do TIPO à competição (cf. Aragão, 1996), o que poderia ser alcançado através do planejamento e desenvolvimento de procedimentos do tipo competitive tendering (cf. Santos e Orrico Filho, 1996). Essa prática, a despeito de ser preconizada pelo arcabouço jurídico nacional, efetivamente não tem sido posta em ação e situações de monopólio têm se perpetuado na provisão dos serviços em diversos estados da federação.

Apesar da preconização de procedimentos do tipo competitive tendering para todas e quaisquer situações ser criticada e posta em dúvida, e outras maneiras de contratação serem defendidas (Hensher and Wallis, 2005), o caso brasileiro está num estágio anterior se comparado a outros países nos quais maiores reformas já foram assumidas pelas agendas dos transportes. Aqui, rodadas iniciais licitatórias, em um nível mais amplo, ainda precisam ser iniciadas, e essa parece ser a tarefa mais difícil a ser enfrentada. Há de se relembrar que o setor tradicionalmente tem sido operado por empresas privadas, sem subsídios públicos, e a exposição dessas companhias à competição é urgente.

De mais a mais, quando da determinação das especificações dos futuros editais das licitações, ter-se-ia uma ótima oportunidade para estabelecer indicadores de desempenho a serem obedecidos pelos futuros operadores.

Também cabe lembrar que, dado o corrente arcabouço constitucional, outras maneiras de delegação dos serviços, tais como recondução de operadores incumbentes, através de performance-based contracts (PBC) (cf. Hensher, 2005), implicariam maiores reformas constitucionais, notadamente alterações no artigo 175 da CF/1988.

O transporte informal tem disputado parcelas do mercado com os sistemas formais e precisa ser trazido à legalidade. Isso beneficiaria o setor, haja vista a adição de novas possibilidades de provisão dos serviços, com o consequente incremento na robustez dos sistemas e maior atendimento das necessidades dos usuários.

Outro fator importante apontado pela aplicação do modelo é a necessidade de transparência no gerencia- mento dos serviços e de disponibilidade de informações confiáveis aos usuários, bem como a importância da existência de unidades responsáveis pela recepção de queixas, reclamações e sugestões.

Dessa forma, as análises mostram que reformas em nível infraconstitucional são necessárias, e que a regulação estatal acerca da provisão dos transportes rodoviários de passageiros tem de perseguir um padrão mais moderno. Para isso também é fundamental a propagação de políticas de formação de recursos humanos no setor, bem como o fortalecimento dos organismos de tutela. A aplicação das diretrizes do modelo de auditagem proposto pode trazer contribuições e despertar os governos quanto à urgência de conferir melhor cuidado e atenção ao setor.

\section{REFERÊNCIAS BIBLIOGRÁFICAS}

AGERBA (2006) Linhas de Transporte Intermunicipal de Passageiros. AGERBA, [S.l.].

(2007) Informação disponível em http://www.agerba.ba.gov.br/projetoCrescendo.htm, 18 set 2007.

Amaral, A. C. C. (2002) Concessão de Serviço Público. $2^{\mathrm{a}}$ ed. Malheiros, São Paulo.

ANTT (2007) Anuário Estatístico 2007 do Transporte Rodoviário Coletivo Interestadual e Internacional de Passageiros. Disponível em http://www.antt.gov.br/passageiro/anuarios/anuario2007/default.h tm, 10 nov 2007.

Aragão, J. (1996) O Novo Direito Concessionário Nacional: e agora, Ônibus Brasileiro? In: Orrico Filho, R. D.; A. Brasileiro; E. Santos e J. Aragão (orgs.) Ônibus Urbano: Regulamentação e Mercados. L.G.E., Brasília, p. 171-187.

Brasileiro, A. e J. Aragão (2000) Serviço Público e Reformas Regulatórias: Experiências Européias e o Caso Brasileiro. Anais do XIV Congresso de Pesquisa e Ensino em Transportes. v. I, p. 153-164. ANPET, Gramado.

Brasileiro, A. e R. D. Orrico Filho (2005) As Agências Regulatórias de Transportes e Telecomunicações: Experiência Brasileira e Francesa. Transportes, v. XIII. ANPET, Rio de Janeiro, p. 5-20.

DETER/SC (2007) Informação disponível em http://www.deter.sc.gov.br/www/index.php?modulo=conteudo\&i nt_seq_secao=6\&int_seq_subsecao=62\&int_seq_conteudo=2, 11 set 2007.

Di Pietro, M. S. Z. (1999) Parcerias na Administração Pública. $3^{\mathrm{a}}$ ed. Atlas, São Paulo.

European Commission (2001) White Paper - European Transport Policy for 2010. Office for Official Publications of the European Communities, Luxembourg.

Gifoni Neto, G. (2002) Instituições Regulatórias do Transporte Rodoviário Intermunicipal de Passageiros: o Caso das Agências Reguladoras Estaduais Brasileiras. Dissertação de Mestrado. Universidade Federal do Rio de Janeiro, Rio de Janeiro.

Gomide, A.A. e F. G. D. Martins (2005) Regulation of the Interurban Coach Services in Brazil. Anais Eletrônicos do $9^{\text {th }}$ International Conference on Competition and Ownership in Land Passenger Transport. THREDBO, Lisbon.

Hensher, D. A. (2005) Looking Forward: What Comes Next in Competition and Ownership of Land Passenger Transport? Disponível em http://www.itls.usyd.edu.au/thredbo10/, 4 dez 2006.

Hensher, D. A. e I. P. Wallis (2005) Competitive Tendering as a Contracting Mechanism for Subsidising Transportation: the Bus Experience. Disponível em http://www.itls.usyd.edu.au/publications/ working_papers/wp2005/itls_wp 05-19.pdf, 12 jan 2006.

IBGE (2007) Pesquisa Anual de Serviços 2005. V. 7. IBGE, Rio de Janeiro.

INTOSAI (2001) Guidelines on Best Practice for the Audit of Economic Regulation. Disponível em: http://www.nao.org.uk/intosai/wgap/ ecregguidelines.htm, 13 nov 2005.

Marshall, J (2000) The Audit of Economic Regulation. Disponível em http://www.nao.org.uk/intosai/wgap/ecreg marshall1.htm, 24/jun/2005. 
Mattos, P.; M. M. Prado; J. P. C. V. da Rocha; D. Coutinho e R. Oliva (2004) Introdução. In: Mattos, P.; M. M. Prado; J. P. C. V. da Rocha; D. Coutinho e R. Oliva (orgs.) Regulação Econômica e Democracia: O Debate Norte-Americano. Editora 34, São Paulo, p. 23-48.

Moraes, L. R. (1997) A Reestruturação dos Setores de Infra-Estrutura e a Definição dos Marcos Regulatórios. In: Rezende, F. e T. B. Paula (coords.) Infra-Estrutura: perspectivas de reorganização. Regulação. IPEA, Brasília, p. 9-42.

Moreira Neto, D. F. (2003) Direito Regulatório. Renovar, Rio de Janeiro.

Rolim, F. A. O. e A. Brasileiro (2005) A Regulação do Transporte Rodoviário Intermunicipal de Passageiros e o Papel dos Tribunais de Contas. Anais Eletrônicos do XIX Congresso de Pesquisa e Ensino em Transportes. ANPET, Recife.

(2006) Uma Proposta de Modelo de Auditagem de Controle Externo para o Atingimento de Boas Práticas Regulatórias no Transporte Intermunicipal Convencional de Passageiros por Ônibus (TIPO). Anais do XX Congresso de Pesquisa e Ensino em Transportes. v. II, p. 905-916. ANPET, Brasília.

Rolim, F. A. O.; A. Brasileiro e J. Aragão (2007) The Economic Regulation of Brazilian Intermunicipal Coach Transport (TIPO): Contributions that May Arise from the Courts of Accounts Role. Anais Eletrônicos do $10^{\text {th }}$ International Conference on Competition and Ownership in Land Passenger Transport. THREDBO, Hamilton Island.

Rolim (2007) Tribunais de Contas e a Regulação do Transporte Intermunicipal de Passageiros por Ônibus (TIPO). Dissertação de Mestrado, Universidade Federal de Pernambuco, Recife.

Santos, E. e R. D. Orrico Filho (1996) O Mercado de Transporte Público Urbano por Ônibus: que Contestabilidade? In: Orrico Filho, R. D.; A. Brasileiro; E. Santos e J. Aragão (orgs.) Ônibus Urbano: Regulamentação e Mercados. L.G.E., Brasília, p. 99-113.

Santos, E. (2000) Concentração em mercados de ônibus urbanos no Brasil: uma análise do papel da regulamentação. Tese de Doutorado. Universidade Federal do Rio de Janeiro, Rio de Janeiro.

Secretaria de Transportes/RJ (2007) Informação disponível em http://www.transportes.ri.gov.br/onibus/onibus intermunicipais.a sp, 11 set 2007.

TCU (2005) Transporte Rodoviário Interestadual e Internacional de Passageiros no Brasil. TCU, Brasília. 